\title{
Historia del tiempo presente:
}

\section{una mirada desde las prácticas de investigación y formación}

\author{
History of the \\ Present Time: \\ A Look at the \\ Practices of \\ Research and \\ Training
}

\author{
História da \\ atualidade: um \\ olhar a partir das \\ práticas de pesquisa \\ e formação
}

Martha Cecilia Herrera* ORCID: https://orcid.org/0000-0003-4170-7822

Vladimir Olaya Gualteros ${ }^{* *}$ ORCID: https://orcid.org/0000-0002-3935-3271

* Socióloga y Magíster en Historia. Doctora en Filosofía e Historia de la Educación. Profesora Emérita y Catedrática Titular de la Universidad Pedagógica Nacional. Integrante del Grupo de investigación Educación y Cultura Política. Correo electrónico: malaquita10@gmail.com

** Licenciado en Lingüística y literatura y Magister en Educación. Estudiante del Doctorado Interinstitucional en Educación- Universidad Pedagógica Nacional, Universidad Distrital y Universidad del Valle. Profesor Ocasional y Titular de la Universidad Pedagógica Nacional. Integrante del Grupo de Investigación Educación y Cultura Política. Correo electrónico: Vlado2380@gmail.com 


\section{Resumen}

Los procesos de violencia política en el continente latinoamericano han sido de larga duración, y han incidido en la formación de las subjetividades. En este contexto, el grupo Educación y Cultura Política fundó un programa de formación e investigación que intenta comprender dichos procesos, a partir de la historia del tiempo presente. En este artículo se describe cómo se ha relacionado la formación y la historia del tiempo presente en los trabajos de investigación llevados a cabo en la búsqueda de la comprensión de la configuración de subjetividades en medio de contextos de violencia política.

\section{Palabras clave}

historia del tiempo presente; memoria; formación; subjetividad; violencia política

Abstract

The processes of political violence in the Latin American continent have been of long duration influencing on the formation of subjectivities. In this context, the group of research Education and Political Culture founded a training and research program that tries to understand these processes through the History of the Present Time. The article describes how the different research works have been relating the formation and History of the Present Time, in order to understanding the configuration of subjectivities in context of political violence.

\section{Keywords}

history of the present time; memory; education; subjectivity; political violence

\section{Resumo}

Os processos de violência política no continente latino-americano têm sido duradouros e influenciaram a formação de subjetividades. Nesse contexto, o grupo Educação e Cultura Política fundou um programa de formação e pesquisa que busca compreender esses processos, a partir da história do tempo presente. Este artigo descreve como a formação e a história da atualidade têm sido relacionadas à pesquisa realizada na pesquisa de uma compreensão da configuração das subjetividades no contexto de contextos de violência política.

\section{Palavras-chave}

história do tempo presente; memória; formação; subjetividade; violência política 


\section{Introducción}

Los procesos de violencia política en Colombia $y$, en general, en la región latinoamericana, han tenido incidencia no solo sobre el cuerpo de los individuos -con miles de víctimas en el país-, sino también sobre el tejido social. La violencia ha llegado a establecer una suerte de ecologías que permean cómo los sujetos se forman e instituyen en diversos espacios sociales y que inciden en la construcción de significados y expresiones relacionadas con las culturas política. En este contexto, el grupo Educación y Cultura Política de la Universidad Pedagógica Nacional fundó, en 2010, un programa de formación e investigación denominado "Configuración de subjetividades y constitución de memorias sobre la violencia política en América Latina", cuyo objetivo central ha sido comprender los procesos de formación dados en medio de la violencia política de nuestro pasado reciente. Para el cumplimiento de este propósito, el grupo de investigación ha acudido al análisis de diversas prácticas sociales, dispositivos de subjetivación, testimonios de víctimas, narrativas testimoniales, diferentes emprendimientos de memoria provenientes de colectivos y organizaciones sociales, así como al análisis de variadas producciones estéticas, como el cine y la fotografía, cuyo objetivo radica en referenciar el pasado violento. En pro del estudio de este corpus documental, el grupo ha configurado como marco comprensivo las elaboraciones provenientes de la historia del tiempo presente. En esta perspectiva, la investigación, titulada "Programa de investigación y formación. Configuración de subjetividades y constitución de memorias sobre la violencia política en América Latina: un estado del arte" (código DPG 449-17), se propuso auscultar los logros y alcances que ha tenido el programa a lo largo de estos años, algunos de cuyos hallazgos se presentan en este artículo, con referencia particular a los modos de análisis y la constitución de sus objetos y sujetos de estudio.

En este sentido, se pretende evidenciar, en una primera parte, las relaciones establecidas desde el programa de investigación entre historia del tiempo presente y formación, para mostrar luego, en una segunda parte, cómo algunos de los trabajos de investigación, llevados a cabo en el marco del programa, se han servido de ella para la comprensión de los procesos de configuración de subjetividades en contextos de violencia política. El corpus documental se configuró con los diversos productos surgidos en el programa, incluyendo proyectos de investigación, tesis de maestría y doctorado, así como publicaciones, entre otros. Para los fines de este artículo, se seleccionaron trabajos que evidenciaban los diferentes acercamientos al estudio de la violencia política desde diversos objetos y sujetos. Así, por ejemplo, trabajos como el de Avella (2016) y Meyer (2013), hacen hincapié en el análisis de los procesos de subjetivación en colectivos sociales. Pérez (2014), Terryl (2016) y Ramírez (2012), dirigen sus indagaciones a poblaciones particulares como mujeres, jóvenes escolares y universitarios. Herrera y Pertuz (2017) centran su investigación en las narrativas y la literatura testimonial, mientras que Cristancho (2013) hace del cine y sus productores los ejes de su trabajo doctoral. De este modo, las investigaciones seleccionadas evidencian las posibilidades analíticas de la violencia política desde el acercamiento a los trayectos y procesos de formación desde diversas experiencias y sujetos.

\section{La historia del tiempo presente y los procesos de formación}

Las reflexiones en torno a las problemáticas relacionadas con la violencia política han cobrado vigor en el continente latinoamericano desde hace varias décadas, acicateadas por las preocupaciones en torno a sus incidencias en el tejido social y en la configuración de las subjetividades, a partir de los regímenes de dictadura o de democracia restringida que caracterizaron la región desde la década de 1960. Lo anterior dio pie a un campo de estudios en el que la memoria se situó como eje y convocó a intelectuales pertenecientes a diferentes campos de las ciencias sociales y humanas en la tentativa de comprender acontecimientos que se ubicaban en el pasado reciente, cuyas incidencias sobre el tiempo presente modulaban gran parte de las significaciones en torno al ejercicio de los regímenes 
políticos, la gubernamentalidad y el lugar de los sujetos políticos dentro de los mismos (Jelin, 2003; Pérotin-Dumon, 2007).

Este campo de estudios buscó reconciliar ámbitos de conocimiento que en un momento habían aparecido como distantes y al buscar historizar la memoria se señalaron las fronteras porosas que separaban historia y memoria, a la vez que se avanzó en formulaciones en torno a la diversidad de las temporalidades que caracterizan la existencia humana y las posibles confluencias, fracturas y/o diferenciaciones entre ellas, apoyándose en aportes provenientes de las ciencias sociales y humanas en torno a esta problemática (Hutton, 1993). De este modo, tiempo histórico y tiempo social dejaron de presentarse como categorías propias de disciplinas que trabajaban de modo separado, llevando a historiadores, sociólogos y otros especialistas a aunar esfuerzos por comprender los estudios de la memoria y la violencia política como un marco en el que confluían problemáticas que llamaban al trabajo interdisciplinario en la configuración de los objetos de estudio que allí comenzaron a emerger.

El advenimiento de los regímenes de transición a la democracia, como fue el caso del Cono Sur, o de tentativas por democratizar espacios caracterizados por formas de represión política o de conflicto armado interno, como Colombia, colocaron en el corazón de la agenda pública los diversos problemas que entraña el abordaje investigativo en torno al pasado reciente y los usos de la memoria en el tiempo presente, dentro de los cuales se encuentra el debate en torno a las políticas de la memoria y sus diversas formas de implementación y apropiación que evidencian la tensión permanente entre los intereses gubernamentales, los derechos de las víctimas y las reivindicaciones de los derechos humanos, espacios en los cuales, como menciona Burke (2011), aflora "el retorno de lo reprimido en el que las memorias no oficiales finalmente se abren paso en la esfera pública" (p. 498).

Pese a este contexto, la historia del tiempo presente y su relación con la forma en que se ha venido estudiando el tiempo histórico, sigue siendo objeto de múltiples debates. En esta perspectiva, comprendemos el estudio del tiempo presente como un constructo reflexivo que teje una serie de relaciones entre lo que ha sido y el momento presente, centrado en la comprensión del momento actual, con lo cual se le ha otorgado vital importancia a las experiencias de los individuos (Fazio, 2010a, 2010b).

Esta entreverada cohabitación de temporalidades permite que la historia del tiempo presente sea el resultado de una historia experimentada, distinta a la idea de una historia recibida, cuyos límites temporales son el producto de una conciencia social trenzada a los acontecimientos vividos y reconocidos por diversas generaciones; es decir, "formada a partir de la experiencia de nuestro propio actuar" (Fazio 2010b, p. 42). Dicha concepción invita a pensar la descripción del tiempo presente lejos de una linealidad, para ver el tiempo como el despliegue de relaciones, en la sincronía, pero también en los vínculos construidos desde una perspectiva diacrónica, es decir; en los modos como el pasado se hace presente en lo coetáneo, en la espacio-temporalidad de los sujetos y las comunidades. Se trata, un poco, del asalto a una tradición histórica que se fundaba en la idea de continuidad, para pensar este nuevo registro histórico como el ahondamiento del momento compartido, del correr por la experiencia que se da en la actualidad; no obstante, no olvida entender que ella está entremezclada y se encuentra en la densidad del tiempo histórico. Esto es, si bien, se funda en la experiencia, entiende, como lo planteó Braudel (1970), que los acontecimientos también hacen a los hombres y las historias particulares se presentan bajo la forma de una serie de acontecimientos. Para Braudel los hechos no pueden ser separados de sus actores, pero a su vez concibe la construcción histórica como sedimentada a través de capas superpuestas, es decir, ella se da en una multiplicidad de temporalidades. Desde esta perspectiva, se podría plantear que la historia del tiempo presente es una temporalidad que registra otras temporalidades, pero también forma parte de una serie de capas que instituyen a los sujetos a lo largo de sus trayectorias. Sin embargo, la diferencia con el estudio de un tiempo de larga, corta o mediana duración, como 
el propuesto desde la óptica del tiempo histórico, se encuentra en que su estudio, más allá de las continuidades, rupturas y permanencias, ahonda en las experiencias vividas por los sujetos.

En esta óptica, el estudio del tiempo presente concibe que este, al igual que el análisis del tiempo histórico, "gravita en el entrelazamiento de diferentes dimensiones, dinámicas y estratos que entran en resonancia" (Fazio 2010b, p. 61). A su vez, comprender los hechos del pasado refiere la identificación de una sucesión de hechos y procesos dados en el tiempo. También implica el ejercicio de narración, explicación y comprensión de situaciones dadas, pero a su vez observar las prácticas sociales y el hacer de los sujetos y de las comunidades. En la construcción de dicho saber histórico entra en juego el tiempo presente por lo menos desde dos ópticas: por un lado, como principio; es desde el presente que se erige una mirada, se constituye una forma de ver y de interpretar el pasado. Y, por otro, como finalidad, por cuanto se edifica el conocimiento histórico en pro de comprender los sucesos y acontecimientos en la contemporaneidad (Fazio, 2010b). En este sentido, el presente es comprendido como irrepetible y en el que se da la presencia y variabilidad de distintos estratos sociotemporales, diferente a la idea de un tiempo presente visto como un hecho que ya fue, que es pasado. El estudio del tiempo presente, entonces, solicita el análisis de lo sincrónico, diferente a cómo ha sido concebida por la historia tradicional en donde existe la preponderancia de lo diacrónico y se olvida en ocasiones la intersección entre varios modos de vivir el pasado en el momento actual; esto es, la mirada a la actualidad de lo no contemporáneo que conlleva a considerar la articulación entre lo diacrónico y lo sincrónico en el tiempo presente (Kosselleck, 1993; Dosse, 2012). En este sentido, el presente funge como un eje en el que se constituyen relaciones entre el pasado vivido, hecho presente, que coadyuva a la construcción de futuro y en el que la experiencia se desvela en la supervivencia de la memoria.

Así, un elemento esencial para la comprensión del tiempo presente es la experiencia, la cual es posi- ble entenderla como viaje, tránsito de los individuos que se pliega en los modos de ser. La experiencia es un pasar a través de, que constituye a los individuos, lo que habla del estar en un momento, en un espacio que transforma al sujeto en su fluir. La experiencia no es solo una categoría de tiempo, es el lugar en que es posible ver los modos como se ha vivido, la forma en que los fenómenos son corporeizados y entrelazados en los modos de actuar y estar en la contemporaneidad a partir de ejercicios de reflexividad. Ahora bien, la memoria cumple un papel fundamental; en ella se enuncia la experiencia. No existe una memoria que no hable del vivir individual o colectivo en sus diferentes dimensiones. A través del recuerdo se edifica una visión de temporalidad, continuidad, por cuanto construye sentido, se configura un orden del pasado vivido. Ella, la memoria, permite ver y reflexionar sobre lo vivido, tejiendo los vínculos que enlazan pasado y presente. Sin la rememoración no tendríamos la posibilidad de elaborar algún tipo de historización. La memoria contiene la experiencia del pasado, es su resorte de conservación, que, al presentarse correlativa a la historia, esta última le sirve como su forma de explicitación permanente y pública (Aróstegui, 2004).

No obstante, la memoria no es el simple ejercicio de traer del pasado los sucesos, sino que existe en su elaboración una resignificación de los acontecimientos a partir de ciertas categorías o conceptos elaborados en el presente o resultado de tradiciones culturales. Así, la memoria se constituye en un ejercicio de interpretación del tiempo humano y es ello lo que la convierte en la posibilidad de construcción de la historicidad. Es claro que la memoria no es historia. Mientras que la primera es una potencialidad humana, modelada de alguna manera por lo social, la historia es registro. No obstante, la historia se debe nutrir de la memoria, pero para que la memoria sea historia, necesita que la misma sea objetivada, se coloque en el punto de vista del grupo, "que pueda denotar que un hecho marca una determinada época porque ha penetrado en el círculo de las preocupaciones y de los intereses colectivos" (Aróstegui, 2004, p. 29). En esta perspectiva, la de las relaciones entre historia y memoria, es posible decir que la historia 
del tiempo presente se nutre de las memorias vivas de los sujetos, de la experiencia y en la que confluyen diversos registros temporales, lo que rompe con el tradicional distanciamiento entre memoria e historia (Ricoeur, 2000). En esta dirección,

\begin{abstract}
Hay que recordar hasta qué punto la historia se ha enriquecido con los acicates de las memorias plurales. Ella no sería lo que es sin este aporte decisivo que la reconfigura en todo momento. Los mayores enriquecimientos de la historia le vienen de la dignificación histórica conquistada por las memorias, ya sea de las mujeres, de las minorías regionales, de las minorías religiosas o de los grupos sociales sin voz. Es este recorrido en la memoria colectiva de las experiencias más diversas el que ha enriquecido constantemente a la historia en su estadio reflexivo e historiográfico.

(Dosse, 2012, p. 108).
\end{abstract}

Ahora bien, es la experiencia la que le ha permitido al programa de formación e investigación, del que se ocupa la investigación a la que hace referencia este artículo, construir vínculos para la comprensión de los procesos de formación y sus relaciones con la historia del tiempo presente. Para ello entendemos a los sujetos como espacial y temporalmente situados, instalados en medio de una serie de relaciones que los ayuda a constituir. Los sujetos son en las relaciones, se constituyen en ellas, se transforman en virtud de los acontecimientos que se dan en el tiempo. Son ellos, los acontecimientos y las relaciones en los cuales están inscritos los sujetos, y a los cuales dan sentido a través de la rememoración, lo que permite elaborar un orden de los sucesos, aunque ellos no sucedan simultáneamente, instituyendo lo que puede denominarse una temporalidad (Elías, 1989). A través de tal configuración se intenta construir una inteligibilidad de los hechos y del acontecimiento, generando un tipo de saber sobre lo sucedido, una forma de orientación resultado no solo de las percepciones individuales sino sociales. En este sentido, el tiempo social, como lo plantea Elías, o el tiempo vivido, como lo postula Ricoeur (2000), es la constitución de una serie de relaciones en las cuales se ven inmersos los sujetos.
La constitución de una temporalidad a través de la memoria y la experiencia nos habla a su vez de procesos de formación que son situados y perceptibles a través de los trabajos de la memoria (Ricoeur, 2000). Lo anterior si comprendemos, por una parte, que la única forma de tener acceso a la experiencia de los otros es la narrativa lenguajeada, pues ella deja ver las maneras como el sujeto se relaciona con el otro y con lo otro. Y, por otra parte, que es a través de la narrativa (en tanto ejercicio de reconstrucción de lo dado) como entendemos los modos en que hay una fractura, continuidad o variación en la constitución subjetiva de los individuos, producto en los procesos de formación de los sujetos, entendidos estos últimos, no solo como el aprendizaje de una serie de saberes sino como una transformación de la experiencia de sí, resultado de la interpelación de diversos factores y espacios sociales en los que el individuo ha estado inmerso (Larrosa, 1995). En este orden de ideas, la formación es un proceso de devenir y construcción constante que se produce en las trayectorias de los sujetos. La formación se expresa en las transformaciones de los sujetos, en sus formas de ver-se, narrar-se, juzgar-se en condiciones particulares y atadas a la experiencia vivida.

De acuerdo con esta concepción de formación, concebimos al sujeto como aquel caracterizado por la capacidad de ser formado, es decir, este no es una entidad uniforme, homogénea, ni acabada; el sujeto es posible de ser permeado, se encuentra en apertura a múltiples posibilidades, lo que dice de un sujeto que se constituye en la exterioridad de las relaciones, en la intersubjetividad, en continuo movimiento y por tanto su construcción biográfica da cuenta de dinámicas que se superponen. Sumado a ello, dicho sujeto es constituido y constituyente de sus entornos y los modos de relación en los que se encuentra inscrito en estos. En este sentido, como lo afirma Verón (2013), dicha cualidad le da un carácter socioindividual. Solo es en sí, por cuanto se encuentra en lo social y en la configuración histórica que lo articula y es allí donde el sujeto constituye su identidad, esto es, en los contextos que lo determinan pero que al mismo tiempo resignifica. Lo anterior habla de un sujeto llegando 
a ser, configurándose en las relaciones significadas y las que, además, se vinculan de diferentes modos con los acontecimientos presentes.

Pensar la formación desde la experiencia, como transformación de la subjetividad, no implica la primacía de lo traumático en nuestro campo de estudios sobre la violencia política y la configuración de subjetividades. Es preciso exponer, por una parte, que si bien no podemos vislumbrar el resultado de las interpelaciones en los sujetos (lo formado), si es posible decir que la violencia, al igual que los diferentes constructos estéticos o artefactos culturales, en cuanto ejercicios simbólicos y comunicativos en diferentes niveles y constituciones éticas, presentan modos de ser y marcos de interpretación de lo social. Es decir, toda práctica social se puede constituir en una invitación a una forma de ser, de pensar y actuar en el mundo. Así, las diferentes formas de interpelación son una suerte de construcción performativa. Esto es, intentan modular una nueva significación, una nueva realidad, pese a ello, es claro que tal intencionalidad solo se hace posible por el grado de afectación y significación de quien es interpelado y son el resultado, además, tanto del momento presente como de las experiencias del pasado, así como de las diversas cargas culturales, cognitivas y emocionales de los individuos. Desde esta óptica, una mirada a la historia del tiempo presente nos ayuda a comprender la singularidad de los modos de vivir una época, las diferentes temporalidades en las que están inscritos los individuos, su comprensión como producto de diferentes situaciones, pero a la vez nos ayuda a observar los modos de transformación de la experiencia de sí en la urdimbre de las temporalidades en las cuales esta se despliega.

\section{El tiempo presente y los modos de comprensión de los procesos de formación}

El problema de estudio que ha delineado el programa de formación e investigación y desde el cual se han formulado proyectos de investigación de los profesores que integran el grupo, así como trabajos de maestría y de doctorado, por parte de estudiantes vinculados al semillero de investigación, gravita en torno a la comprensión de las diversas modalidades referidas a la configuración de las subjetividades en medio de contextos violentos a partir de la segunda mitad del siglo xx en Colombia y en algunos países de América Latina, como Chile y Argentina (Herrera, 2013).

Pese a la diferencia en los objetos de estudio de cada uno de los trabajos, en la mayoría se devela una opción política relacionada con dirigir la mirada a las víctimas, mucho más que a los victimarios, por un lado, y, por otro, cuando se alude a construcciones como las del cine, la fotografía, o las narrativas testimoniales, se estudió cómo se representa a la víctima y las formas en que tales construcciones simbólicas inciden en los procesos de formación y educación de los sujetos. En esta perspectiva, las situaciones, las construcciones estéticas, los sujetos, individuales y colectivos, objeto de análisis, responden a una mirada de época y a una preocupación por la situación actual del país y a los elementos comunes o distantes a otros países latinoamericanos.

Sin embargo, las posturas analíticas, así como los contextos que son enunciados en los objetos de estudio, no se asumen desde una mirada dicotómica, esto es, entre buenos y malos. Los estudios que miran víctimas de la violencia política explican los fenómenos sociales, los hechos del pasado reciente como marcos en los que los individuos se configuran. En este sentido, la violencia no es referenciada tan solo como un aglomerado de eventos. A través de ella se configuran unas condiciones en las que diversos sujetos existieron y tuvieron alguna experiencia y en la que se constituye y se despliega la configuración de subjetividades. Ello es visible, por ejemplo, en la tesis de maestría Memoria, rupturas y formación de las subjetividades políticas en el movimiento estudiantil de la Universidad del Atlántico (Terryl, 2016). Dicho trabajo tiene como centro de reflexión los procesos de formación de líderes estudiantiles, en medio de una época teñida por la muerte de activistas políticos y sociales, pero que en la voz de dichos individuos nos dejan ver la forma 
como se constituye una etapa de nuestra historia. Para el autor del trabajo referenciado:

Estos testigos [los líderes estudiantiles de la Universidad del Atlántico que fueron entrevistados] son un medio para estudiar el pasado reciente, los conflictos en la universidad pública, permitiendo comprender de qué modo la violencia política durante las décadas de los ochenta y los noventa alteró sustancialmente la aceptación conceptual que se tenía hasta ese momento del conflicto social y político del país. (Terryl, 2016, p. 23).

Se comprende, desde la tesis referenciada, que existe una época caracterizada por una serie de hechos violentos que no pueden ser vistos tan solo como un conflicto político, social y económico, este se corporiza en unos modos de ser sujeto, de comprender y percibir el mundo. De hecho, la voz de uno de los líderes estudiantiles, el trasegar por su historia de vida, nos deja ver cómo la violencia de nuestro pasado reciente incide en las formas como el sujeto se percibe, cómo transforma su experiencia de sí, pero también la manera en que hechos como los consumados por el paramilitarismo, objeto de diversos estudios sociológicos e históricos, cobran otros sentidos en donde las víctimas superan la idea de una pura subjetividad receptora de la violencia:

La misma situación de la universidad nos llevaba al tropel, siempre estábamos haciendo cosas, siempre estábamos haciendo tomas, manifestaciones, tropeles, haciendo cosas y actividades desde lo cultural... [Exigíamos] una universidad democrática, pública, al servicio del pueblo, tanto en el valor de la matrícula como en los contenidos que se enseñaban en ésta [...]. Cuando el rector de la Universidad del Atlántico, Ubaldo Enrique Meza, se vio arrinconado por la forma como nosotros lo atacábamos y denunciábamos la corrupción no hubo más si no que aliarse con el paramilitarismo, pues se sabe que ellos (los paramilitares) fueron los que nos mataron, nos volaron la sede, nos desplazaron a varios compañeros. (Terryl, 2016, p. 58).

Se puede deducir del trabajo de investigación que las condiciones sociales, políticas y económicas de una época particular, así como hechos violentos concretos de un tiempo reciente, se van entreverando para constituirse en el marco de actuación de unas posiciones de sujeto. No obstante, este marco no imposibilita que los sujetos los modulen dichas interpelaciones a partir de constructos y representaciones sociales adquiridas en diferentes escenarios. Es decir, el sujeto se hace en el registro de lo social y en la multiplicidad de agenciamientos que ella constituye y que se materializan en diferentes momentos y espacios sociales, haciendo que los procesos de formación, subjetivación, sean descentrados y dinámicos. Así, al mirar la historia del tiempo reciente, en su centramiento en la experiencia de los individuos nos posibilita entender cómo el sujeto se va constituyendo, pero al tiempo los modos en que, en este caso particular, los hechos de violencia cobran un sentido particular, dependiendo de unas características de los sujetos, sus contextos particulares y sus formas de significar los mismos acontecimientos.

En este orden de ideas, eventos como asesinatos selectivos y masivos, desapariciones forzadas, desplazamiento forzado de una comunidad específica, un atentado, enfrentamientos entre diferentes grupos armados legales e ilegales, implementación de una política pública en pro de la guerra o la consecución de la paz, desaparición o el secuestro de un líder político, campesino, indígena o estudiantil, son leídos como elementos que caracterizan una época, los cuales no se encuentran, como lo demuestra la contextualización histórica que hace el trabajo antes referido, desarticuladas de un tiempo largo, de una serie de sucesos pertenecientes a la larga historia de la violencia política del país y que permiten entender las disputas políticas, territoriales, económicas o ideológicas. Sin embargo, estas, a la vez, iluminan la comprensión en torno a la configuración de los sujetos en medio de acontecimientos violentos, es decir, el modo en que esta serie de sucesos configuran una lógica de actuación y un escenario de enunciación y de prácticas sociales que se constituyen en modos de subjetivación.

Esta manera de perfilar el análisis dice de un acercamiento al pasado que observa su densidad en los modos de vida que este coadyuva a configurar. 
Se trata de dar privilegio a la comprensión del fenómeno por parte del sujeto, lo que es diferente a relatar las causalidades, los actores o el desarrollo del conflicto, que, si bien es importante y necesario, nos deja en el borde de los fenómenos. Así, por ejemplo, la mirada al desplazamiento forzado, realizada desde la sociología, la historia o el trabajo social, lo entienden como el resultado de la violencia, como factor expulsor de la población, en principio generado por luchas partidistas, pero también debido a pugnas económicas en torno a la tenencia de la tierra entre campesinos, colonos y latifundistas, iniciadas incluso desde el siglo XIX. En contraste con esta mirada, en otro vértice que no olvida estos factores macroestructurales, resultado de una serie de sucesos en un tiempo de larga y mediana duración, desde la mirada propiciada por la historia del tiempo presente y los procesos de formación de los sujetos, el desplazamiento forzado adquiere unas características específicas con directa incidencia en las configuraciones de los sujetos. En este sentido, la tesis de maestría de Lina María Ramírez (2012) se plantea un tipo de análisis de la vivencia de las mujeres que entiende como:

[...] la experiencia del desplazamiento forzado está sujeta a la relación entre los habitantes y su entorno, es decir a la cosmogonía construida alrededor de su territorio, lo que en un sentido retributivo es alimentado por una serie de aprendizajes sociales como resultado de procesos de formación ética y política [...]. El interés por los procesos de formación ético-política de las mujeres en condición de desplazamiento forzoso aparece cuando se abordan los retos que las mujeres en condición de desplazamiento deben atender respecto a las transformaciones de su identidad y subjetividad, especialmente en los casos que demandan su participación en escenarios públicos que tradicionalmente fueron ocupados por los hombres de su entorno. (p. 45).

Este tipo de investigaciones enfatizan en los sujetos y se valen para su comprensión del testimonio, el relato autobiográfico, la historia de vida, pero no como una suerte de memoria de los hechos traumáticos, sino como los sentidos, modos de vivir y enfrentar vivencias que inciden en el tiempo presente de los sujetos. Así, la mirada a unos tiempos largos, a las tradiciones culturales de los sujetos y a la vez, al modo en que los individuos constituyen una experiencia permite desvelar las formas como un pasado cobra un tipo de presencia particular en los modos en que los sujetos asumen una posición, a la vez que exhiben una transformación de la experiencia de sí. De lo anterior es ejemplo, también, la tesis de doctorado de Andrés Avella (2016), quien se centra en el desplazamiento y en las vivencias de las poblaciones del bajo Atrato y busca comprender las condiciones que posibilitaron el desalojo, pero a su vez cómo este fenómeno atraviesa a los individuos y transforma sus subjetividades. Avella nos advierte que los orígenes del desplazamiento y los modos de operar de diferentes agentes del conflicto tienen que ver no solo con una intención de ocupar el territorio, sino con agenciar una desarticulación de las culturas políticas, relacionadas con la etnicidad y la apropiación del lugar que habían logrado construir las comunidades negras del Chocó, lo cual los llevó a procesos de desubjetivación y de posterior reconfiguración subjetiva. En este orden, su trabajo procura:

[...] identificar los significados dados por los miembros y por las comunidades del bajo Atrato, al conjunto de sus experiencias vitales como víctimas del desplazamiento forzado. Es decir, los significados dados a todo aquello que vivieron cuando su desplazamiento se fraguaba, cuando no tuvieron más opción que partir en huida, y cuando retornar o adaptarse se mezcló como objetivos inalcanzados, en una cotidianidad irresuelta que para algunos se prolongó por años. (Avella, 2016, p. 32).

Esta perspectiva le permite, desde el acercamiento al testimonio y a la vida de comunidades y organizaciones, sondear la particularidad de los fenómenos, ubicarlos en un momento y espacio situado, lo cual le permite resolver algunas de las dificultades que se presentan al tratar de hablar de la violencia, en abstracto, como fue recurrente en trabajos como el de Colombia: violencia y democracia (Comisión de Estudios sobre la Violencia, 1987). 
De este modo, este acercamiento se detiene en las implicaciones de los acontecimientos de violencia en los modos de vivir de los individuos, en pro de la identificación de las formas en que estos sucesos, dados en un pasado reciente, reverberan en el presente, en las prácticas de los sujetos y en los modos en que ellos se perciben y se reconfiguran. En la misma lógica lo identifica Ramírez (2012), cuando aborda el desplazamiento de mujeres en la cuenca del río Ariari, como efecto de la lucha entre guerrilla y paramilitares, así como de la resonada política de seguridad democrática, evidenciando la manera en que una serie de hechos, entrelazados con los pasados culturales de los individuos, propician una serie de significados a los hechos de violencia que lo explican y lo hacen comprensible en sus dimensiones individuales y colectivas:

Junto a los cambios en su contexto y en respuesta a ellos, las mujeres enfrentan procesos de formación por los cuales aprenden a asumir nuevas posiciones de sujeto mujer dando lugar a una mixtura entre los roles que desempeñaban en la zona como mujer esposa, mujer madre, mujer vecina, mujer hermana, mujer ama de casa, para sumarle posicionamientos subjetivos como mujer asalariada, mujer analfabeta, mujer desplazada, mujer foránea, mujer desempleada, mujer víctima, mujer viuda, mujer amenazada [...]. En el marco de esos cambios de posiciones de sujeto, las mujeres se ven abocadas a vivir diversidad de situaciones que las enfrentan a la desolación y la desesperanza, sus fibras más íntimas son trastocadas y puestas en jaque. (Ramírez, 2012, p. 122).

Algunas de las investigaciones (Ramírez, 2012; Castro, 2012; Calvachi, 2015), resultado del programa de formación, relacionan los modos como los acontecimientos vividos en el pasado reciente se van tejiendo en la vida y configuran la experiencia de los individuos en el tiempo presente. Esto es, las memorias de los individuos permiten desvelar las maneras en que los sujetos relacionan en el presente configuraciones históricas devenidas de los espacios sociales expresadas en tradiciones, hábitos, imaginarios culturales, las cuales son liadas por los sujetos en el proceso de significación de las experiencias de la violencia y coadyuvan a entender sus prácticas sociales en el momento presente.

En este sentido, es posible evidenciar que varios de los trabajos de investigación comprenden el tiempo presente como la confluencia de diferentes temporalidades y que el mismo no desecha una serie de registros temporales que se van sedimentando en la vida de los individuos que son quienes nos pueden ayudar, finalmente, a comprender cómo es posible referir una época, caracterizar los modos en que se vive una guerra y entender lo histórico, no como una suma de acontecimientos sino como resultado de procesos compuestos por múltiples dimensiones sociales, culturales y políticas en donde los sujetos manifiestan diversos agenciamientos. Ello es posible verlo en la tesis de maestría de Miller Antonio Pérez (2014), quien ve en la narrativa de jóvenes afectados por la violencia política el entrecruzamiento de una tradición histórica, intrincada a una temporalidad y espacialidad particular, la cual cobra vigencia en la manera como se vive y valora la violencia y la justicia. Dicha mirada posibilita entender que, en territorios como el Casanare, en algunos casos, la participación en grupos al margen de la Ley no tenía que ver tan solo con la acción de reclutamiento obligado por parte de la guerrilla o los paramilitares, sino con el modo en que una tradición cultural, como la llanera, entiende la defensa de lo que se concibe como propio. Esto es, según los relatos que logra acopiar Pérez, con jóvenes de la región del Ariari, muchos hombres de la región entendían que unirse a los grupos al margen de la ley era sinónimo de valentía, hombría y rescate de aquello que se había construido por años de estancia en la región. En este sentido, la guerra, la violencia, no se trata tan solo de lo legal o ilegal, sino lo que se considera legítimo, lo cual está asociado a concepciones tradicionales, construidas en temporalidades largas, respecto a las formas de ser hombres y de enfrentar la vida y las dificultades en medio de un espacio y un territorio particular.

En esta misma perspectiva, los sentidos de la violencia política, para los jóvenes que participaron del trabajo de investigación de Pérez, se encuentran 
relacionados con representaciones mítico-religiosas. Así, por ejemplo, el desmembramiento de un sujeto, los cuerpos destrozados y dejados en los caminos en los sitios rurales, se convierte no solo en evidencia del horror de la guerra o del enfrentamiento político y económico, sino que dichos sucesos se explican desde una valoración moral, ligada a una vertiente cristiana, como resultado de buenas o malas acciones, o como producto de algún tipo de acción cometida por alguien, lo que se puede sintetizar en una frase como: "Por algo habrá sido" (Pérez, 2014, p. 78).

Algunos de los trabajos (Gómez, 2013; González Y., 2013) muestran de qué modo una causalidad histórica puede ser objeto de análisis en el momento presente y así evidenciar los lazos con los modos como los sujetos han hecho frente al hecho violento dejando emerger tramas del conflicto que permiten su comprensión desde las significaciones de los individuos. Desde este ángulo, el trabajo Del movimiento a la insurrección armada: bases sociales y económicas del conflicto en el norte del Tolima (Meyer, 2013), retoma elementos de una historia general que explica la época de la violencia desde una lucha bipartidista e identifica en esta zona la génesis de las FARC, pero se centra en las diversas experiencias organizativas a partir de los procesos comunitarios. El estudio de estos procesos, a través de la voz de algunos de sus protagonistas, permitió dilucidar la manera en que se daban las luchas por la tierra, por el mercado del café en la región, pero también la emergencia de una serie de movilizaciones que posibilitaron la formación política de los campesinos y el despliegue de formas de resistencia que coadyuvaron al fortalecimiento del entramado comunitario para hacer frente a los fenómenos de violencia. Desde este tipo de análisis es posible revelar y comprender cómo, en ocasiones, algunas agrupaciones campesinas no dudaron en recibir el apoyo de uno u otro partido dependiendo de sus posiciones estratégicas e intereses, pero con la intención de utilizar dicho auxilio en pro de la consolidación de la organización campesina local. Tal perspectiva alienta a entender la violencia como un fenómeno multidimensional en el que los agen- tes del conflicto no pueden ser vistos en una sola posición, sino en diversas dinámicas relacionales.

En este sentido, el trabajo de investigación muestra, por una parte, el origen de diferentes organizaciones en la región del Tolima, tales como la Asociación Nacional de Usuarios Campesinos (ANuC), la Asociación de Pequeños y Medianos Cafeteros (APEMECAFE), el Gremio Cafetero Unido, ligados a procesos históricos pero a la vez a una serie de relaciones asimétricas entre sujetos y organizaciones sociales, que dejaron emerger complejos procesos de formación de los sujetos en contextos de violencia. Sumado a lo expuesto, la articulación entre una historia nacional, con hechos, testimonios y circunstancias particulares, rompe con la lógica de la revictimización de muchos de los actores del conflicto y señala cómo la comprensión de las dinámicas de la guerra reciente implica entender las formas en que los individuos las viven y procesan, lo cual también da luces en torno a sus reconfiguraciones subjetivas en aras a proyectar un futuro marcado por escenarios de posconflicto.

Como se ha visto en los trabajos citados en líneas anteriores, el análisis de la experiencia trabada en una contemporaneidad, pero a la vez leída en su interrelación con narrativas históricas mucho más largas, permite, por un lado, la comprensión de la manera en la que los acontecimientos sociales y fenómenos como los de la violencia son mucho más que eventos en un espacio particular de tiempo, ellos adquieren una serie de significaciones particulares en contextos determinados, lo que permitiría no solo hablar de múltiples violencias, sino de la diversidad de biosferas violentas, entendidas como espacios en los que los sujetos configuran sus interrelaciones y se dan procesos de formación de subjetividades. En este sentido, el estudio del tiempo presente, anudado a los procesos de formación, posibilita acercarse a los ensamblajes sociales, los que son dinámicos, conflictivos y responden al establecimiento de una serie de asociaciones heterogéneas y no a una serie de características estables en el tiempo.

Ahora bien, cuando el corpus principal de las investigaciones son los testimonios de quienes han 
experienciado la violencia política (López, 2015; Peña, 2016), se puede percibir cómo estos ordenan el tiempo en torno a la mirada del presente, a lo configurado en el hoy, a los sentidos construidos entre la memoria de lo que fue y de lo que se está siendo en la vida cotidiana. Tal mirada es, por lo general, parcial, fragmentaria, nunca totalizante. Aun así, es claro que esta forma del pasado está anclada mucho más a las rupturas de los individuos en sus modos de ser, pensar y actuar, que a una fecha o un evento particular. El quiebre de los sujetos, las marcas en la subjetividad o la solidificación de procesos de identificación son el modo, en que, en muchas de las ocasiones, se ordena el pasado y sobre el cual se van sobreponiendo nuevos eventos, otras personas, hasta la evidencia de otra transformación en los modos en que se ven y narran los individuos. No obstante, las investigaciones no se quedan con una sola voz ni intentan procurar la verdad de lo acontecido. Buscan, en la mayoría de los casos, encontrar elementos similares en una multiplicidad de voces, o sus diferencias, alertando que ellas devienen de una posición de los sujetos en medio del conflicto. Así, las comprensiones de los investigadores en torno a la formación y el tiempo reciente, con base en estos corpus, se vuelven entreveradas, sinuosas, y permiten comprender como el pasado adquiere sentido.

En las investigaciones que hemos enunciado, la manera en que se vive el presente, producto de la experiencia del pasado, desvela las fracturas y transformaciones de la experiencia de sí, resultado de interpelaciones de diferente índole y que conlleva procesos de formación de subjetividades, de desubjetivación y de reconfiguración subjetiva en distintos momentos del tiempo. Esto es, los trabajos al examinar las temporalidades a través de los hechos rememorados, o a través de producciones culturales tales como el cine, la fotografía o la literatura testimonial, muestran la construcción no solo de diversas subjetividades, sino la lucha por una serie de significados que intentaban educar en torno a una serie de significados sociales. Así, por ejemplo, la tesis doctoral Tigres de papel, recuerdos de película. Memoria, oposición y subjetivación política en el cine argentino y colombiano (Cristancho, 2013), aborda la producción de cine en Colombia y Argentina que tiene que ver con la transición a la democracia en Argentina y los procesos de paz en los años 1980 en Colombia y la forma en que en ella se ha mostrado la oposición política.

La investigación exhibe cómo diversas configuraciones históricas, sociales y políticas fueron coadyuvando a la construcción de nuevos regímenes visuales, esto es, a constituir una serie de visibilidades a través de las cuales se ordena y significa lo social evidenciadas, por un lado, en un tipo de producción audiovisual y, por otro, en las narrativas de las producciones culturales que instituyen un tipo de subjetividad política, en este caso, de oposición a un discurso imperante. La tesis retoma los acontecimientos de la historia de violencia de cada uno de los países, su relación con unas circunstancias en el tiempo presente y los procesos de formación de los productores en distintos espacios, para pensar desde allí en el modo como confluyen, tensionan e hibridan diferentes discursos, enunciados y visibilidades que tienen concreción en construcciones estéticas específicas en el campo cinematográfico. Así, el análisis de la historia del tiempo presente posibilita ver los cambios en los regímenes visuales, pero a su vez, el modo en que los sujetos resignifican, transforman y producen modos de ver que son desplegados en la arena de lo público, pugnando por un tipo de significados políticos y sociales. La tesis demuestra, entonces, cómo las configuraciones subjetivas, así como el tiempo presente, no se componen por ellos mismos, sino que en su constitución tienen incidencia la historia y los espacios que la precedieron, por un lado, y que los diferentes modos en que los sujetos ven y constituyen significaciones en el mundo social se expresan a través de distintas construcciones simbólicas y estéticas, por otro; pero que es precisamente en dichas elaboraciones en las que se evidencia el resultado y la concreción de los procesos de formación, entendiendo esta última como una suerte de movimiento pendular que conjuga lo que se ha sido, lo que se es y la posición en la cual se ubica el individuo en el espacio social en el cual se encuentra inserto. 
En esta misma lógica, otros trabajos de investigación han abordado las narrativas testimoniales, en sus diversos registros, para entender de qué modo un momento histórico constituye a los individuos y modula las condiciones de posibilidad de lo que es posible decir y desde qué lugar es posible decirlo. A partir de este reconocimiento, se entienden estas producciones culturales, las narrativas testimoniales, como lugares para la comprensión del pasado reciente y las formas como acontecimientos de violencia política actúan en la afección de los cuerpos, en la implementación de políticas de destrucción e incluso de desaparición de diversas configuraciones de cultura política. Se trata, como pretensión investigativa, de ver en los relatos individuales, las maneras en que los acontecimientos sociales cobran una suerte de materialidad en las configuraciones subjetivas. En este sentido, al remitirse a la voz de los testimoniantes, se busca comprender un momento histórico y no solo la determinación de acontecimientos traumáticos en la vida de los individuos, es decir, verlos en las relaciones sociohistóricas en la que estos fueron constituidos, lo cual da luces tanto en lo referente a las subjetividades como a los entornos políticos y culturales. Desde esta perspectiva ha sido interesante identificar, en diversas experiencias de la violencia política, como ella, además de quebrantar los cuerpos, fragmenta los modos en que los sujetos se perciben y pueden cambiar las formas como los sujetos miran el pasado y los modos del actuar en el presente, con incidencia en los horizontes de futuro; es decir, la violencia modula cambios en las formas de cómo se ven los sujetos, pero sumado a ello, a través de la narrativa testimonial, estos también constituyen ejercicios de reflexividad que les permiten tramitar la transformación de sus experiencias (Herrera y Pertúz, 2017).

\section{Conclusiones}

Como es posible advertirlo, la pregunta por la formación en las investigaciones inscritas en el programa de formación e investigación del grupo de investigación Educación y Cultura Política, se inscribe en fenómenos amplios del pasado reciente, lo cual posibilita comprenderla en el engranaje dinámico de los procesos sociales, en la configuración de un tiempo histórico y social determinado, que tiene en cuenta la experiencia de los individuos y las maneras de tramitar los acontecimientos relacionados con la violencia política. Estas interrelaciones permiten, a su vez, desvelar a qué elementos responden una serie de resignificaciones de los individuos y el modo en que transitan en los entramados sociales. Así mismo, permiten comprender la violencia más allá de los eventos que la caracterizan o una secuencia de sucesos, sino como una acción proceso mediada por múltiples vectores y por las experiencias de los sujetos.

Lo anterior solicita, entonces, que nos acerquemos a la construcción de una representación de la violencia política que supere un tipo de narrativas enclaustradas en los agentes o en los meros efectos que propicia, para pensarla como resultado de acontecimientos que obturan y fragmentan los modos en que hombres y mujeres han sido constituidos en medio de dinámicas culturales, políticas, sociales que les obligan a desconfiar de sus propias convicciones $y$, en muchas ocasiones, los obligan a ser de otro modo. El problema de la violencia política no son solo sus consecuencias, las muertes o las disputas, ella se enclava en lo más profundo de los seres humanos constituyendo el horror, lo inenarrable. No existe una única imagen del horror, ni de la guerra, concurren múltiples imágenes y encadenamientos significativos y el acercamiento a ellos es lo que debemos contar, explicar y comprender, siempre en un espacio temporal histórico particular. Por lo anterior, es que entendemos necesario acercarnos a los procesos de formación desde la perspectiva de la historia del tiempo presente, pues esta más que ser una forma narrativa de la historia, es entendida como una postura comprensiva que permite acceder a la intelección de los sucesos históricos desde el sentido, pero también desde las transformaciones de los sujetos, pues son esos modos de ser, resultado de una serie de acontecimientos, los que dicen de una época.

En los diversos trabajos de investigación, resultado del programa de formación e investigación, llevados a cabo por el grupo Educación y Cultura 
Política, dentro de los cuales se incluyeron tesis de maestría y doctorado, como una forma de agenciamiento de procesos de formación de las nuevas generaciones en el campo de estudios sobre memoria y violencia política, se retomaron objetos de estudio cuyos corpus documentales se centraron en testimonios y narrativas, y se pudo percibir cómo este tipo de elaboraciones se instituyen como los lugares en los que los sujetos trenzan diferentes temporalidades y dejan ver la variedad de posiciones de sujetos en la trama histórica social. Esto es, los sujetos en la constitución de sus subjetividades inscriben una serie de saberes, construcciones culturales y políticas resultado de la experiencia histórica, de su pertenencia a grupos y movimientos que en un momento dado hicieron resistencia a regímenes políticos represivos bajo los efectos de una violencia macro, vivencias que, una vez fueron afectados por la violencia política, tuvieron que resignificar en ocasiones a través de la desubjetivación, pero en un momento posterior a través de la reconfiguración subjetiva. Ahora bien, observar ello permite, además de comprender las formas en que se transforma la experiencia de los sujetos, cómo una época cobra sentido en la corporalidad/ subjetividad de los individuos. Es la forma, como lo hemos dicho en líneas anteriores, en la que el pasado se hace presente, pero también la manera en que la violencia política de un momento histórico se traduce no solo en acciones contra la vida física, sino en cómo ella implica las mutaciones de los modos de pensar, sentir y actuar de los individuos traducida, en muchas de las ocasiones, en el borramiento de un pensamiento, un proyecto ideológico, una idea de hombre y mujer, de sociedad, que seguramente habría tenido incidencia en el mundo social y económico. Así, la mirada a los procesos individuales y colectivos permite y coadyuva a entender cómo el trasegar histórico y los fenómenos sociales dicen de sus efectos y pervivencias en el presente, a través de los procesos de transformación de la experiencia de sí de los sujetos.

\section{Referencias}

Avella, E. (2016). Desplazamiento y subjetivación. El caso de los desplazados de la cuenca del bajo Atrato. (Tesis de doctorado). Universidad Pedagógica Nacional, Bogotá.

Aróstegui, S.J. (2004). Retos de la memoria y trabajos de la Historia. Revista de Historia Contemporánea, 3, 5-51.

Braudel, F. (1970). La historia y las ciencias sociales. Madrid, España: Alianza Editorial.

Burke, P. (julio-diciembre de 2011). Historias y memorias: un enfoque comparativo. ISEGORÍA, Revista de Filosofía Moral y Política, 45, 489-499.

Calvachi, A. (2015). Resonancias Existenciales. Historia de vida de una maestra del Distrito. (Tesis de Maestría). Universidad Pedagógica Nacional. Bogotá, Colombia.

Castro, C. (2012). Aportes de la memoria histórica a la formación ético-política de jóvenes familiares de militantes de la Unión Patriótica. (Tesis de Maestría en Educación). Universidad Pedagógica Nacional. Bogotá, Colombia.

Comisión de Estudios sobre la Violencia (1987). Colombia: violencia y democracia. Bogotá, Colombia: Universidad Nacional de Colombia.

Cristancho, J.G. (2013). Tigres de Papel, recuerdos de película. Memoria, oposición y subjetivación política en el cine argentino y colombiano. (Tesis de doctorado). Universidad Pedagógica Nacional. Bogotá, Colombia.

Dosse, F. (2012). El giro reflexivo de la historia. Recorridos y la atención a las singularidades. Santiago de Chile, Chile: Ediciones Universidad de Finis Terrae.

Elías, N. (1989). Sobre el tiempo. México: Fondo de Cultura Económica.

Fazio, H. (2010a). La historia global y el estudio del presente. En J.Á. Bresciano (ed.), El tiempo presente como campo historiográfico. Ensayos teóricos y estudios de caso (pp. 115-136). Uruguay: Ediciones Cruz del Sur.

Fazio, H. (2010b). La historia del tiempo presente. Historiografía, problemas y métodos. Bogotá: Universidad de los Andes.

Gómez, H. (2013). Educación y subjetividad política en la plataforma social de Usme. (Tesis de Maestría). Universidad Pedagógica Nacional. Bogotá, Colombia. 
González, Y. (2013). Encrucijadas por la memoria y subjetividades políticas en el colegio Orlando Higuita Rojas I.E.D. (Tesis de maestría). Universidad Pedagógica Nacional. Bogotá, Colombia.

Herrera, M.C. (2013). Entre Mnemosine y Clío: las pulsaciones de la experiencia humana. En G.G. Vargas y A. Ruíz (ed.), Cátedra Doctoral. Campo Intelectual de la educación y pedagogía (pp. 147-170). Bogotá: Universidad Pedagógica Nacional.

Herrera, M. y Pertuz, C. (2017). Subjetividades caleidoscópicas, relatos y espejos trizados. Narrativas testimoniales sobre violencia política en América Latina y políticas de la memoria. Bogotá: Universidad Pedagógica Nacional.

Hutton, P. (1993). History as an art of Memory. Vermont: University of Vermont.

Jelin, E. (octubre de 2003). Los derechos humanos y la memoria de la violencia política y la represión: la construcción de un campo nuevo en las ciencias sociales. Cuadernos de IDES, 2. Recuperado de http://biblioteca.clacso.edu.ar/gsdl/collect/ar/ar-025/ index/assoc/D4331.dir/cuaderno2_Jelin.pdf

Kosselleck, R. (1993). Futuro pasado. Por una semántica de los tiempos históricos. Barcelona: Paidós.

Larrosa, J. (1995). Tecnologías del yo y educación (Notas sobre la construcción y la mediación de la experiencia de sí). En J. Larrosa, Escuela, poder y subjetivación (pp. 259-328). Madrid: Ediciones La Piqueta.

López, A. (2015). Ser maestra. Historia de vida. (Tesis de Maestría en Educación). Universidad Pedagógica Nacional. Bogotá, Colombia.
Meyer, D. (2013). Del movimiento a la insurrección armada: bases sociales y económicas del conflicto en el norte del Tolima. (Tesis de maestría). Universidad Pedagógica Nacional. Bogotá, Colombia.

Peña, L. (2016). Entre el miedo y la esperanza. (Tesis de Maestría en Educación). Universidad Pedagógica Nacional. Bogotá, Colombia.

Pérez, M. (2014). Memorias de la violencia política en la narrativa de jóvenes escolares del sur del departamento del Casanare. (Tesis de maestría). Universidad Pedagógica Nacional. Bogotá, Colombia.

Pérotin-Dumon, A. (2007). Liminar. Verdad y Memoria: escribir la historia de nuestro tiempo. En A. PérotinDumon (dir.), Historizar el pasado vivo en América Latina. Recuperado de http://etica.uahurtado.cl/ historizarelpasadovivo/es_contenido.php .

Ramírez, L. (2012). Emprendimientos de memoria y formación ético-política de mujeres en condición de desplazamiento forzado. Encuentros con mujeres del bajo y medio Ariari. (Tesis de maestría). Universidad Pedagógica Nacional. Bogotá, Colombia.

Ricoeur, P. (2000). La memoria, la historia, el olvido. Buenos Aires: Fondo de Cultura Económica.

Terryl, R.L. (2016). Memoria, rupturas y formación de las subjetividades políticas en el movimiento estudiantil de la Universidad del Atlántico. (Tesis de maestría). Universidad Pedagógica Nacional. Bogotá, Colombia.

Verón, E. (2013). Semiosis social 2. Ideas, momentos, interpretaciones. Buenos Aires, Argentina: Paidós. Estudios de comunicación. 